Published in final edited form as:

Cell Motil Cytoskeleton. 2003 July ; 55(3): 213-220.

\title{
Requirement for the $\beta_{1}$ and $\beta_{\mathrm{IV}}$ Tubulin Isotypes In Mammalian Cilia
}

\author{
Heather C. Jensen-Smith ${ }^{1}$, Richard F. Ludueña ${ }^{2}$, and Richard Hallworth ${ }^{*}$ \\ 1Department of Biomedical Sciences, Creighton University, Omaha, Nebraska \\ 2Department of Biochemistry, The University of Texas Health Science Center at San Antonio
}

\begin{abstract}
[Nielsen et al., 2001: Curr Biol 11:529-533], based on studies in Drosophila, have proposed that $\beta$ tubulin in axonemal microtubules must contain a specific acidic seven amino acid sequence in its carboxyl terminus. In mammals, the two $\beta_{\mathrm{IV}}$ isotypes $\left(\beta_{\mathrm{IVa}}\right.$ and $\left.\beta_{\mathrm{IVb}}\right)$ contain that sequence. In order to test the application of this hypothesis to mammals, we have examined the expression of $\beta$ tubulin isotypes in four different ciliated tissues (trachea, ependyma, uterine tube, and testis) using isotypespecific antibodies and indirect immunofluorescence. We find that $\beta_{\mathrm{IV}}$ tubulin is present in all ciliated cell types examined, but so is $\beta_{\mathrm{I}}$ tubulin. Taken together with recent studies that show that $\beta_{\mathrm{I}}$ and $\beta_{\text {IV }}$ tubulin are both present in the cilia of vestibular hair cells, olfactory neurons, and nasal respiratory epithelial cells, we propose that both $\beta_{\mathrm{I}}$ tubulin and $\beta_{\mathrm{IV}}$ tubulin may be required for axonemal structures in mammals.
\end{abstract}

\section{Keywords}

tubulin isotypes; cilia; trachea; ependyma; Fallopian tube; testis

\section{INTRODUCTION}

Tubulin is the ubiquitous structural protein in microtubules consisting of $\alpha$ and $\beta$ monomers in 1:1 stoichiometry. $\beta$ tubulin exists in seven different isotypes in mammals, each the product of a separate gene [Ludueña, 1998]. The seven different isotypes, named $\beta_{\mathrm{I}}, \beta_{\mathrm{II}}, \beta_{\mathrm{III}}, \beta_{\mathrm{IV} \text { a }}$, $\beta_{\mathrm{IVb}}, \beta_{\mathrm{V}}$, and $\beta_{\mathrm{VI}}$, have unusually similar amino acid sequences. These sequences are considered among the most highly conserved in evolution. For example, the chicken and mouse $\beta_{I}$ isotypes differ in only two residues [Ludueña, 1998]. This sequence conservation in mammals and other vertebrates is consistent with the multitubulin hypothesis, the idea that the isotypes perform different functions [Fulton and Simpson, 1976]. However, functional correlations to specific isotypes have been hard to obtain.

Although it is now clear that cells selectively express $\beta$ tubulin isotypes, it has been hard to ascribe a specific function to a particular isotype. In this context, Nielsen et al. [2001] have proposed that isotypes with a particular amino acid sequence in the carboxyl terminus (EGEFXXX, where $\mathrm{X}$ is any acidic amino acid) are required for normal axonemal function. The Nielsen et al. [2001] study was performed in Drosophila. In mammals, this sequence is present only in $\beta_{\mathrm{IV}}$ tubulin, which is in fact two essentially identical isotypes, $\beta_{\mathrm{IVa}}$, and $\beta_{\mathrm{IVb}}$. Although four isotype-specific antibodies are now available [Roach et al., 1998], the distribution of $\beta_{\mathrm{I}}, \beta_{\mathrm{II}}, \beta_{\mathrm{III}}$, and $\beta_{\mathrm{IV}}$ tubulin isotypes has not been previously studied systematically in ciliated tissues ( $\beta_{\mathrm{IVa}}$, and $\beta_{\mathrm{IVb}}$ are indistinguishable). Previous reports have indicated that $\beta_{\mathrm{IV}}$ tubulin is a common constituent of cilia, but that other isotypes are also

*Correspondence to: Richard Hallworth, Department of Biomedical Sciences, Creighton University, 2500 California Plaza, Omaha, NE 68178. E-mail: hallw@creighton.edu 
present. In vestibular hair cells, $\beta_{\mathrm{I}}$ and $\beta_{\mathrm{IV}}$ tubulin occur in the single non-motile cilium [Perry et al., 2003]. In the sensory cilia of olfactory neurons, all four isotypes are found, while the cilia of cells of the adjacent nasal respiratory epithelium possess $\beta_{\mathrm{I}}$ and $\beta_{\mathrm{IV}}$ tubulin [Woo et al., 2002]. The latter cilia are motile. Thus, the isotypes common to cilia in these preparations are $\beta_{\mathrm{I}}$ and $\beta_{\mathrm{IV}}$ tubulin.

Therefore, we examined the distribution of $\beta$ tubulin isotypes in adult gerbil ciliated tissues that have not previously been examined: brain ependyma, fallopian tube, testes, and trachea. Taken together with previous studies of vestibular hair cells and nasal sensory and respiratory epithelia, this encompasses nearly all ciliated tissues in the body. We find that both $\beta_{\mathrm{I}}$ and $\beta_{\mathrm{IV}}$ tubulin are common to all cilia. We suggest, therefore, that both $\beta_{\mathrm{I}}$ and $\beta_{\mathrm{IV}}$ tubulin may be required for axonemes in mammals.

\section{MATERIALS AND METHODS}

The distribution of $\beta$ tubulin isotypes was examined in adult gerbil ciliated tissues using indirect immunofluorescence in frozen sections. Adult gerbils ( 20 days old or older) were anesthetized with Nembutal and cardiac-perfused with $10-15 \mathrm{ml}$ of $4 \%$ paraformaldehyde in phosphate buffered saline (PBS). The tissues (trachea, brain, uterus, and testis) were dissected out and were processed to equilibration in $30 \%$ sucrose in PBS as a cryoprotectant and quickly frozen in O.C.T. (Miles Labs, Elkart, IN). Sections 8 to $10 \mu \mathrm{m}$ thick were cut on a cryostat (Leica Microsystems, Bannockburn, IL).

Sections were blocked and permeabilized in PBS containing $1 \%$ bovine serum albumin (BSA), $0.25 \%$ Triton-X, and $5 \%$ normal goat serum. The presence of $\beta$ tubulin isotypes was detected with monoclonal antibodies to the $\beta_{\mathrm{I}}, \beta_{\mathrm{II}}, \beta_{\mathrm{IIII}}$ or $\beta_{\mathrm{IV}}$ tubulin isotypes, raised in mouse as previously described [Banerjee et al. 1988,1990,1992; Roach et al. 1998]. Each antibody was prepared to an epitope unique to the C-terminus of that isotype. The $\mathrm{C}$-termini of $\beta_{\mathrm{IV}}$ and $\beta_{\mathrm{IVb}}$ are almost identical, differing by only two residues, and therefore the anti- $\beta_{\mathrm{IV}}$ antibody was unable to discriminate between them. The primary antibody was made visible by staining with goat anti-mouse IgG coupled to Alexa 488 (Molecular Probes, Eugene, OR). Sections and whole mounts were sealed under coverslips in 50\% PBS: 50\% glycerol containing 1\% npropylgallate as an anti-fade agent. Negative controls were performed by omitting the primary antibody.

Specimens were photographed using an Axioskop II microscope (Carl Zeiss Jena, Jena, Germany) equipped with 40X and 100X objectives. Images were obtained using a Spot RT digital camera (Diagnostic Instruments, Sterling Heights, MI) and were analyzed and prepared for presentation using Photoshop (Adobe Systems, San Jose, CA). Confocal images were obtained on a Radiance 2000 confocal microscope (Bio-Rad, Hercules, CA) on a Nikon Eclipse 800 upright microscope equipped for epifluorescence (Nikon Instruments, Melville, NY). Some video images were obtained using a M.T.I. CCD72 video camera (Dage-M.T.I., Michigan City, IN) on a Nikon Eclipse 800 upright microscope equipped for epifluorescence (Nikon Instruments).

Animal care and handling was performed in conformance with approved protocols of the Creighton University School of Medicine Institutional Animal Care and Use Committee.

\section{RESULTS}

For Figure 1-Figure 4, we show on the left a transmitted light view (under Nomarksi differential interference contrast), and on the right the corresponding immunofluorescence view. 


\section{Tracheal Epithelium}

The lining of the trachea is a pseudo-stratified epithelium consisting of basal cells, mucousproducing (goblet) cells, brush cells, and ciliated cells [Geneser, 1986]. Cilia-bearing cells were observed in clumps lining the lumen of the trachea. In sections of trachea, cilia were labeled by the antibodies to $\beta_{\mathrm{I}}$ tubulin (Fig. 1A,B) and $\beta_{\mathrm{IV}}$ tubulin (Fig. 1G,H). Other cell types, many unidentified, were labeled by the antibody to $\beta_{\mathrm{I}}$ tubulin. However, only ciliated cells were labeled by the $\beta_{\text {IV }}$ tubulin antibody. Cilia were not labeled by the antibodies to $\beta_{\text {II }}$ tubulin (Fig. 1C,D) and $\beta_{\text {III }}$ tubulin (Fig. 1E,F). Some labeling for $\beta_{\text {III }}$ tubulin was seen deep in the epithelium, possibly representing innervation (indicated by the arrow). In the Nomarski images, cilia are indicated by $c$, pseudostratified epithelium by $p e$, and goblet cells by $g c$.

\section{Brain Ependyma}

In brain, the ependyma is a simple cuboidal epithelium lining the ventricles [Geneser, 1986]. Ciliated ependymal cells were most often observed lining the third ventricle, but were also observed in the first and second ventricles. Ciliated cells were often seen lining the choroid epithelium. In ependyma, like trachea, cilia were labeled by the antibodies to $\beta_{\mathrm{I}}$ tubulin (Fig. $2 \mathrm{~A}, \mathrm{~B}$ ) and $\beta_{\mathrm{IV}}$ tubulin (Fig. $2 \mathrm{G}, \mathrm{H}$ ), but were not labeled by the antibodies to $\beta_{\mathrm{II}}$ tubulin (Fig. $2 \mathrm{C}, \mathrm{D}$ ) and $\beta_{\mathrm{III}}$ tubulin (Fig. 2E,F). In the Nomarski images, the cilia are indicated by $c$ and the ventricle is indicated by $v$.

\section{Uterine Tube}

The lining of the uterine tube (also referred to as the oviduct and the Fallopian tube) is a columnar epithelium consisting of mucosal cells and ciliated cells [Geneser, 1986]. Ciliated cells were most often observed lining the uterine tube in the infundibulum and ampulla, close to the ovary. As in ependyma and trachea, ciliated cells were labeled by the antibodies to $\beta_{\mathrm{I}}$ tubulin (Fig. 3A,B) and $\beta_{\mathrm{IV}}$ tubulin (Fig. 3G,H), but were not labeled by the antibodies to $\beta_{\mathrm{II}}$ tubulin (Fig. 3C,D) and $\beta_{\mathrm{III}}$ tubulin (Fig. 3E,F). In the Nomarski images, the cilia are indicated by $c$ and the lumen is indicated by $l$.

\section{Testis}

In the efferent duct of the testis, the lining is a columnar epithelium consisting of ciliated cells and absorptive cells [Geneser, 1986]. As in the uterine tube, ependyma, and trachea, cilia were labeled by the antibodies to $\beta_{\mathrm{I}}$ tubulin (Fig. 4A,B) and $\beta_{\mathrm{IV}}$ tubulin (Fig. 4G,H). They were not labeled by the antibodies to $\beta_{\text {II }}$ tubulin (Fig. 4C,D) and $\beta_{\text {III }}$ tubulin (Fig. 4E,F). In the Nomarski images, the cilia are indicated by $c$, smooth muscle by $s m$, and connective tissue by $c t$.

\section{DISCUSSION}

Our results are in agreement with previous studies of $\beta$ tubulin isotype expression in other ciliated tissues. Perry et al. [2003] showed that vestibular hair cells, each of which possesses a single cilium, display $\beta_{\mathrm{I}}$ and $\beta_{\mathrm{IV}}$ tubulin in the cell body and cilium. Woo et al. [2002] demonstrated that all four isotypes were present in olfactory neurons, including the sensory cilia. Nasal respiratory epithelial cells, which possess motile cilia, displayed $\beta_{I}$ and $\beta_{I V}$ tubulin. Thus both $\beta_{\mathrm{I}}$ and $\beta_{\mathrm{IV}}$ tubulin are common to cilia. In a previous study, Renthal et al. [1993] demonstrated the presence of $\beta_{\mathrm{IV}}$ tubulin in bovine tracheal epithelial cells and in the cilium of photoreceptors. However, the $\beta_{\mathrm{I}}$ tubulin was not available for that study. Roach et al. [1998] showed $\beta_{\mathrm{IV}}$ tubulin in ciliated cells of the uterine wall but they did not find $\beta_{\mathrm{I}}$ tubulin there.

The axoneme-specific sequence (EGEFXXX) proposed by Nielsen et al. [2001] is present only in the carboxyl terminus of the $\beta_{\mathrm{IV}}$ tubulins [Lu et al., 1998]. However, the analogous sequence 
in the carboxyl terminus of $\beta_{I}$ tubulin (EEDFGEE) is perhaps the closest of the other $\beta$ tubulins. This is not surprising since $\beta_{\mathrm{I}}$ tubulin is closely related to $\beta_{\mathrm{IV}}$ tubulin and represents perhaps a relatively recent evolutionary divergence [Ludueña, 1998].

Why are the other isotypes present in only some ciliated cells? We have seen so far that whatever isotypes are present in cilia are also present in microtubules in the remainder of the cell. It is possible that ciliated cells will use any available isotype to synthesize axonemes but must use $\beta_{\mathrm{I}}$ and $\beta_{\mathrm{IV}}$ tubulin. It is interesting in this regard to note the observations of Woo et al. [2002] in olfactory sensory epithelia. Expression of $\beta_{\text {IV }}$ tubulin was demonstrated in mature olfactory neurons but not in basal cells, the stem cells of olfactory neurons. Olfactory neurons undergo a regular cycle of replacement every 40 days or so, in which they are replaced by maturing basal cells. Basal cells express the other three isotypes but not $\beta_{\text {IV }}$ tubulin. It appears then that basal cells only express $\beta_{\mathrm{IV}}$ tubulin when it is needed to make axonemes.

It is perhaps not surprising that two highly conserved tubulin isotypes occur in many types of cilia. The ciliary axoneme, whose structure is extraordinarily conserved in evolution, is a highly complex structure in which three structurally and functionally distinct populations of microtubules occur. First, there are the two microtubules of the central pair, whose role may be to organize the beating motion of the axoneme. These are each singlet microtubules. Then there are the unusual outer doublet microtubules. Each of these nine outer doublets consists of two tubules designated A and B. The A-tubule is a complete microtubule with 13 protofilaments; the B-tubule is an incomplete microtubule of 10 protofilaments attached to the A-tubule. Among other proteins, the A-tubule binds to one end of the dynein complex. The Btubule binds to the other end. By binding to the A-tubule of one outer doublet microtubule and "walking" on the B-tubule of the adjacent outer doublet, dynein causes sliding of the doublets and hence generates the bending motion of the axoneme. It is also possible that one of the protofilaments of the B-tubule is the unrelated protein tektin. In short, the central pair microtubules, the A-tubule and the B-tubule, differ in the proteins to which they bind as well as in their apparent functions. The A- and B-tubules are also structurally different. This is all consistent with axonemes containing more than one tubulin isotype. Future experiments with electron microscopy will address the specific distributions of the $\beta_{\mathrm{I}}$ and $\beta_{\mathrm{IV}}$ tubulin isotypes among the axonemal microtubules.

\section{ACKNOWLEDGMENTS}

Supported by N.I.H. grant CA26376, U.S. Army grant DAMD17-98-1-8246, and Welch Foundation grant AQ-0726 to R.F.L., and N.I.H. grant DC02053 to R.H. H.C.J-S. is a Clare Booth Luce fellow. We thank David Nichols for help in the dissections and Levi Ward, Becky Van Winkle, and Dayton Young for technical assistance.

Contract grant sponsor: NIH; Contract grant numbers: CA26376, DC02053; Contract grant sponsor: U.S. Army; Contract grant number: DAMD17-98-1-8246; Contract grant sponsor: Welch Foundation; Contract grant number: AQ-0726.

\section{REFERENCES}

Banerjee A, Roach MC, Wall KA, Lopata MA, Cleveland DW, Ludeña RF. A monoclonal antibody against the type II isotype of $\beta$-tubulin. Preparation of isotypically altered tubulin. J Biol Chem 1988;263:3029-3034. [PubMed: 3277964]

Banerjee A, Roach MC, Trcka P, Ludueña RF. Increased microtubule assembly in bovine brain tubulin lacking the type III isotype of $\beta$-tubulin. J Biol Chem 1990;265:1794-1799. [PubMed: 2404018]

Banerjee A, Roach MC, Trcka P, Ludueña RF. Preparation of a monoclonal antibody specific for the class IV isotype of $\beta$-tubulin. Purification and assembly of $\beta_{\mathrm{II}}, \beta_{\mathrm{III}}$, and $\beta_{\mathrm{IV}}$ tubulin dimers from bovine brain. J Biol Chem 1992;267:5625-5630. [PubMed: 1544937] 
Fulton, C.; Simpson, PA. Selective synthesis and utilization of flagellar tubulin. The multi-tubulin hypothesis. In: Goldman, R.; Pollard, T.; Rosenbaum, J., editors. Cell motility. vol. 3. Cold Spring Harbor, NY: Cold Spring Harbor Laboratory Press; 1976. p. 987-1005.

Geneser, F. Textbook of histology. Philadelphia: Lea and Fibiger; 1986. 831 p.

Lu Q, Moore GD, Walss C, Ludueña RF. Structural and functional properties of tubulin isotypes. Adv Struct Biol 1998;5:203-227.

Ludueña RF. The multiple forms of tubulin: different gene products and covalent modifications. Int Rev Cytol 1998;178:207-275. [PubMed: 9348671]

Nielsen MG, Turner FR, Hutchens JA, Raff EC. Axoneme-specific $\beta$-tubulin specializations: a conserved C-terminal motif specifies the central pair. Curr Biol 2001;11:529-533. [PubMed: 11413005]

Perry B, Jensen-Smith H, Ludueña RF, Hallworth R. Differential expression of $\beta$ tubulin isotypes in gerbil vestibular end organs. Journal of the Association for Research in Otolaryngology. 2003(DOI: 10.1007/S10162-002-2048-4) in press

Renthal R, Schneider BG, Miller MA, Ludueña RF. $\beta_{I V}$ is the major $\beta$-tubulin isotype in bovine cilia. Cell Motil Cytoskeleton 1993;25:19-29. [PubMed: 8519065]

Roach MC, Boucher VL, Walss C, Ravdin PM, Ludueña RF. Preparation of a monoclonal antibody specific for the class I isotype of $\beta$-tubulin: The $\beta$ isotypes of tubulin differ in their cellular distributions within human tissues. Cell Motil Cytoskeleton 1998;39:273-285. [PubMed: 9580378]

Woo K, Jensen-Smith HC, Ludueña RF, Hallworth R. Differential expression of $\beta$ tubulin isotypes in gerbil nasal epithelia. Cell Tissue Res 2002;309:331-335. [PubMed: 12172793] 

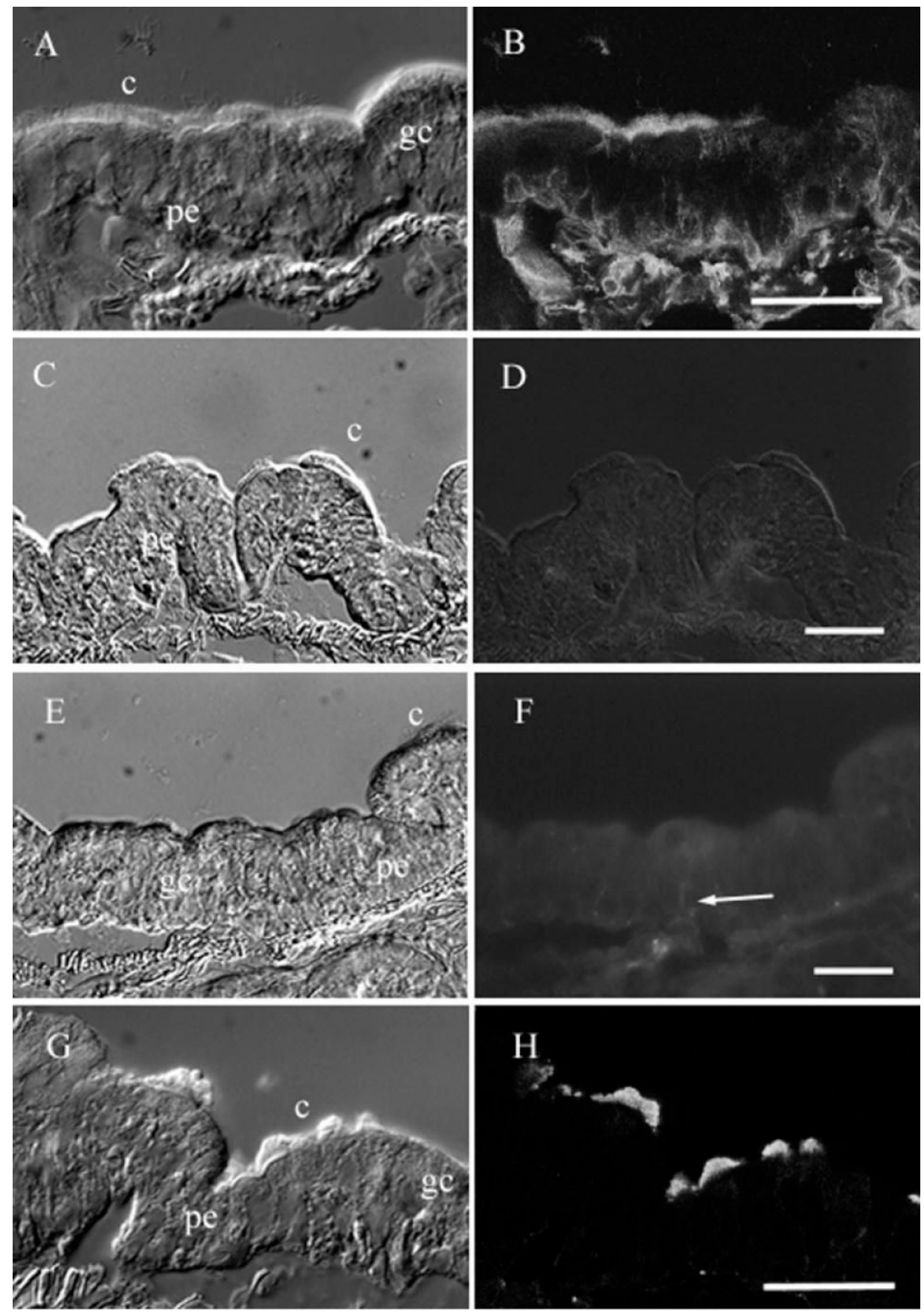

Fig 1.

$\beta$ tubulin isotypes in trachea. $\beta_{\mathrm{I}} \mathbf{A}$ : Transmitted light image of tissue lining the trachea. B: In the same section, the $\beta_{\mathrm{I}}$ antibody labels cilia in trachea as well as non-ciliary microtubules in the pseudo-stratified epithelium. $\beta_{\text {II }}$. C: Transmitted light image of tissue lining the trachea. D: The $\beta_{\text {II }}$ antibody does not label cilia in trachea. $\beta_{\text {III }}$. E: Transmitted light image of tissue lining the trachea. F: The $\beta_{\text {III }}$ antibody does not label cilia in trachea. The arrow indicates possible labeling of innervation. $\beta_{\text {IV }}$ G: Transmitted light image of tissue lining the trachea. H: The $\beta_{\text {IV }}$ antibody labels cilia in trachea. c, cilia; pe, psuedo-stratified epithelium; gc, goblet cell. The scale bars $=30 \mu \mathrm{m}(\mathrm{A}, \mathrm{B}, \mathrm{G}, \mathrm{H})$ and $50 \mu \mathrm{m}(\mathrm{C}-\mathrm{F})$. 

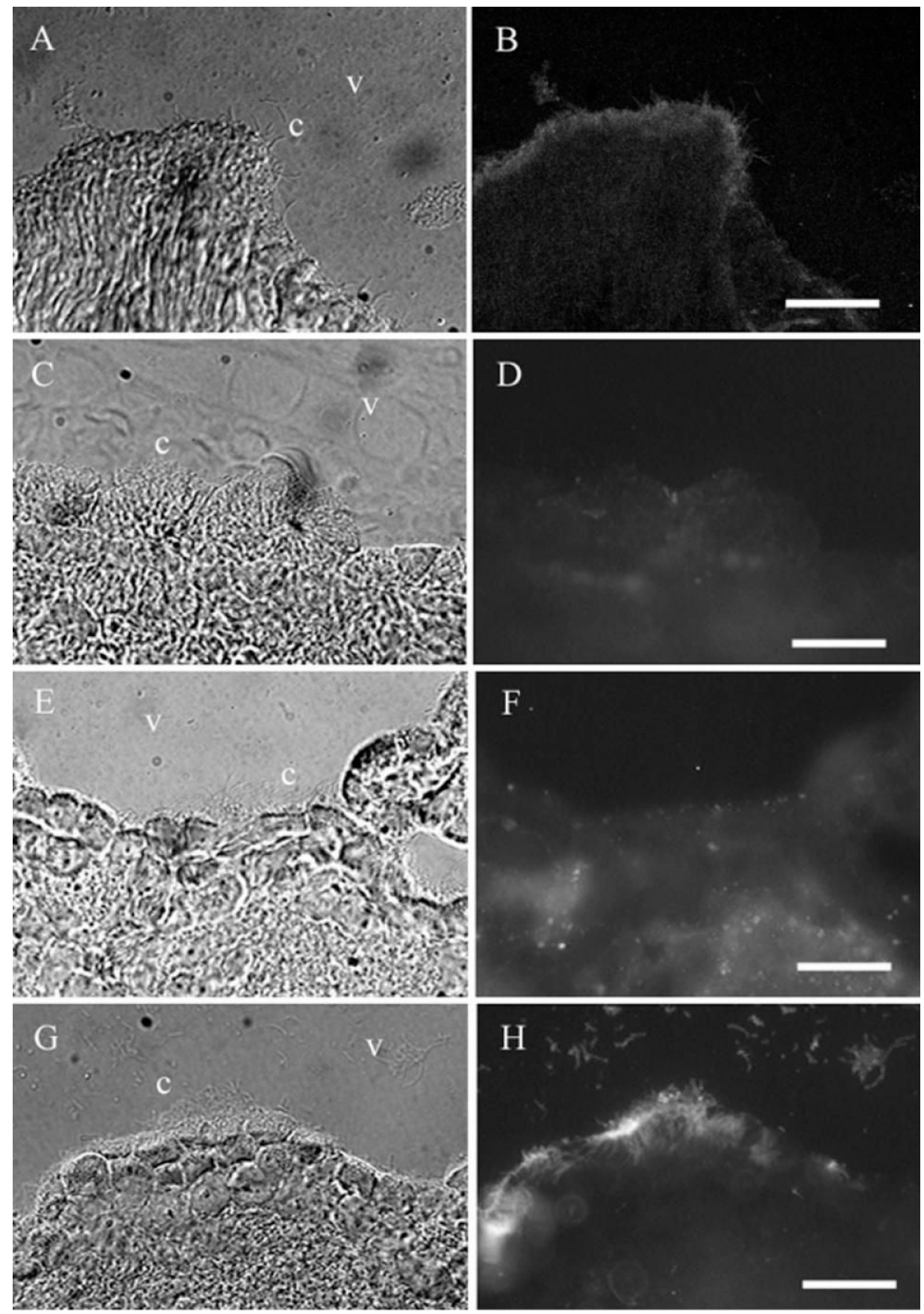

Fig 2.

$\beta$ tubulin isotypes in brain ependyma. $\beta_{\mathrm{I}}$. A: Transmitted light image of ependyma in ventricles of brain. B: The $\beta_{\mathrm{II}}$ antibody labels cilia in ependyma. $\beta_{\mathrm{II}}$. C: Transmitted light image of ependyma in ventricles of the brain. D: The $\beta_{\mathrm{II}}$ antibody does not label cilia in ependyma. $\beta_{\text {III. }}$ E: Transmitted light image of ependyma in ventricles of the brain. F: The $\beta_{\text {III }}$ antibody does not label cilia in ependyma. $\beta_{\mathrm{IV}}$. G: Transmitted light image of ependyma in ventricles of the brain. Note the presence of $\beta_{\text {III }}$ in non-ciliary neuronal tissue. $\mathbf{H}$ : The $\beta_{\text {IV }}$ antibody labels cilia in ependyma. c, cilia; $\mathrm{v}$, ventricle. The scale bars $=30 \mu \mathrm{m}(\mathrm{A}, \mathrm{B})$ and $50 \mu \mathrm{m}(\mathrm{C}-\mathrm{H})$. 

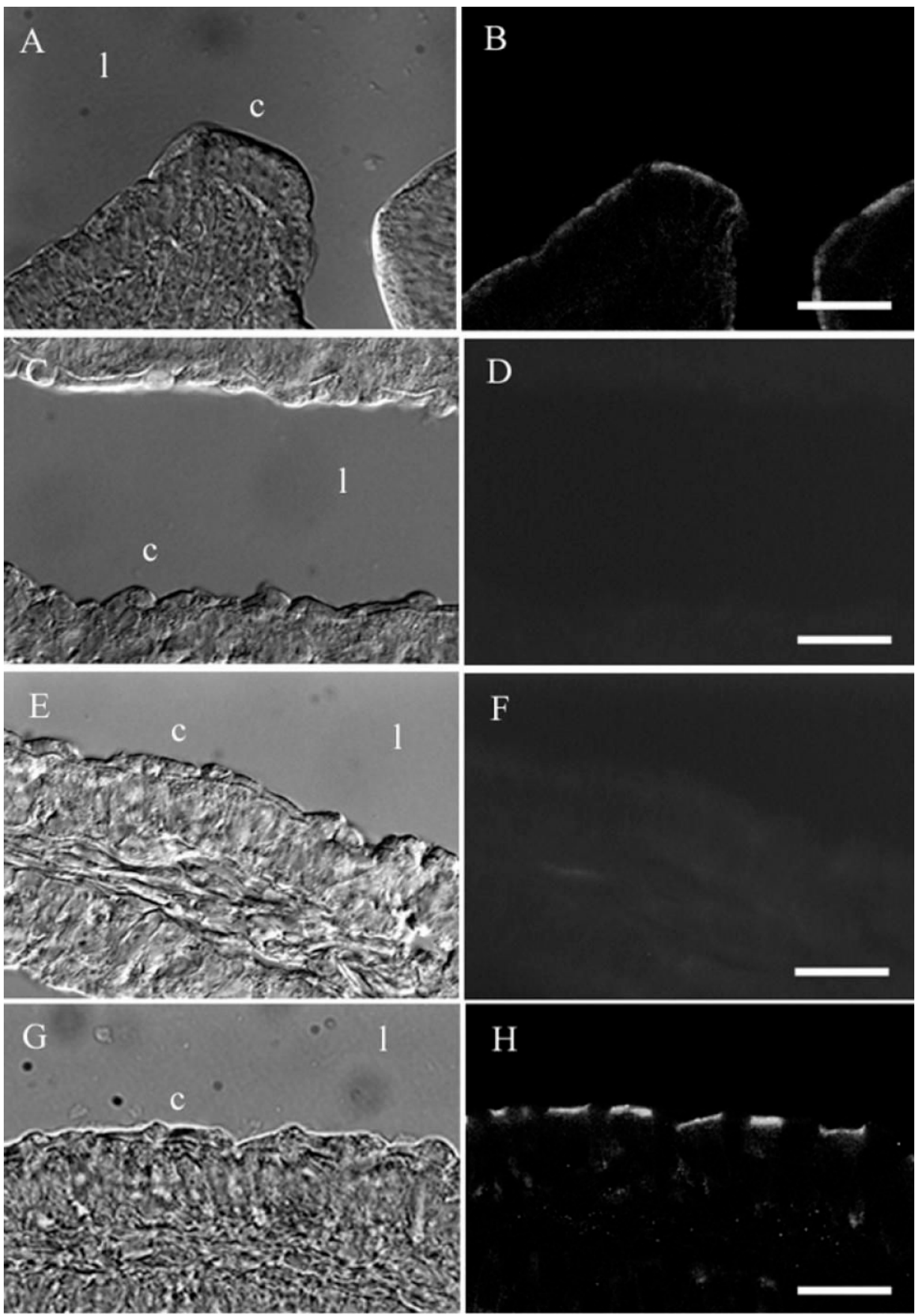

\section{$\mathrm{H}$}

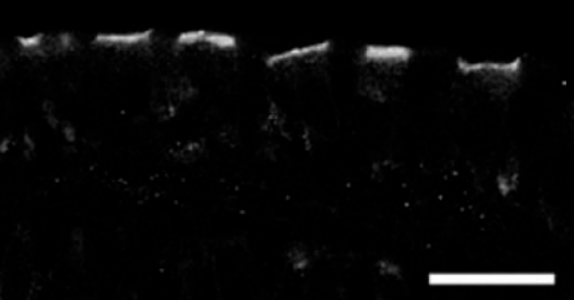

Fig 3.

(Overleaf) $\beta$ tubulin isotypes in uterine tube. $\beta_{\mathrm{I}}$. A: Transmitted light image of ciliated tissue in uterine tube. B: The $\beta_{\mathrm{I}}$ antibody labels cilia in uterine tube. $\beta_{\mathrm{II}}$. C: Transmitted light image of ciliated tissue in uterine tube. D: The $\beta_{\text {II }}$ antibody does not label cilia in uterine tube. $\beta_{\text {III }}$. E: Transmitted light image of ciliated tissue in uterine tube. F: The $\beta_{\mathrm{III}}$ antibody does not label cilia in uterine tube. $\beta_{\text {IV. }}$ G: Transmitted light image of ciliated tissue in uterine tube. H: The $\beta_{\text {IV }}$ antibody labels cilia in the lumen of the uterine tube. $c$, cilia; 1 , lumen. The scale bars $=30$ $\mu \mathrm{m}(\mathrm{A}, \mathrm{B}, \mathrm{G}, \mathrm{H})$ and $50 \mu \mathrm{m}(\mathrm{C}-\mathrm{F})$. 

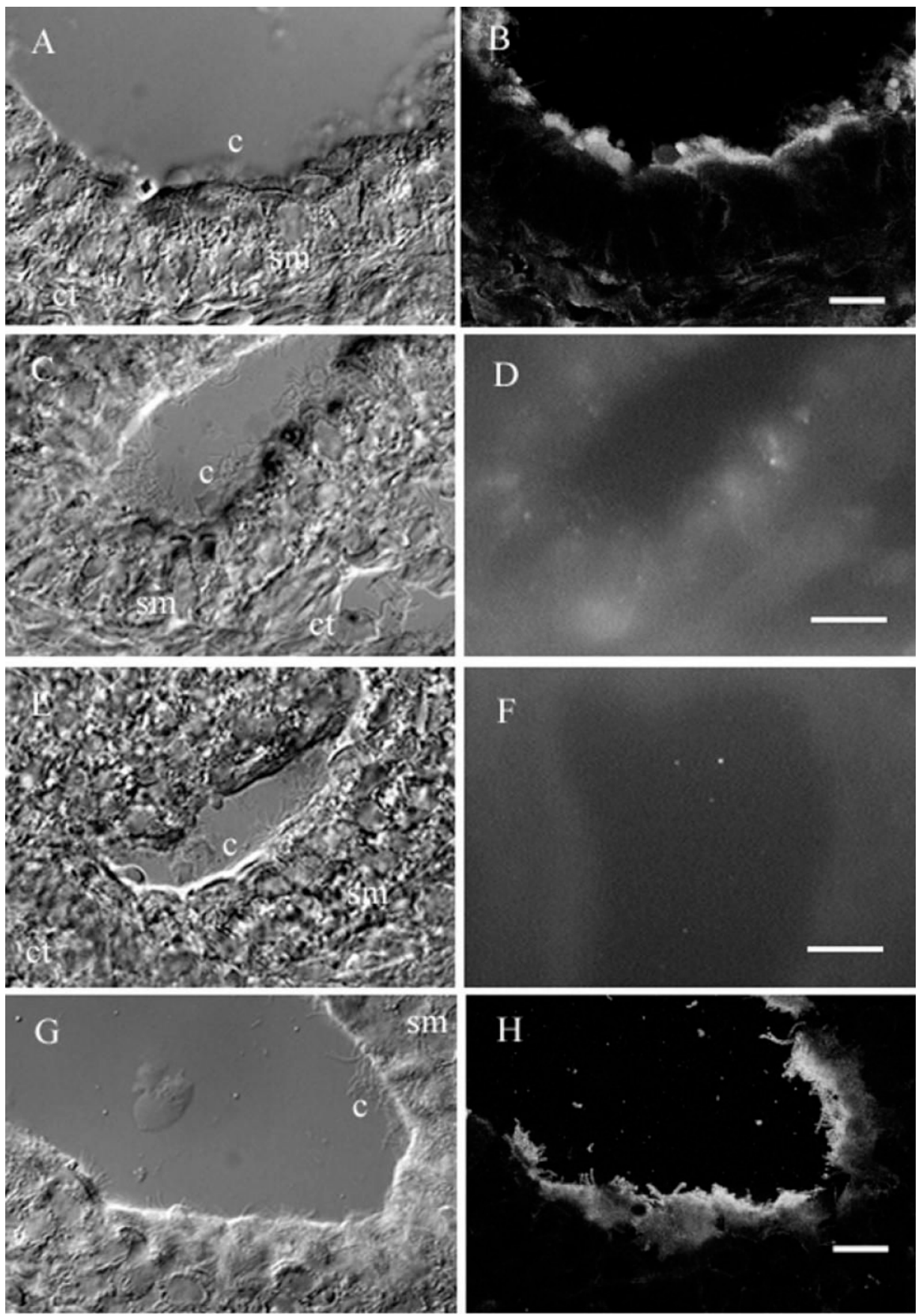

Fig 4.

(Overleaf) $\beta$ tubulin isotypes in testis. $\beta_{\mathrm{I}}$. A: Transmitted light image of efferent ducts in testis. B: The $\beta_{\mathrm{I}}$ antibody labels cilia in efferent ducts as well as non-ciliary microtubules in the connective tissue as well as non-ciliary microtubules in the connective tissue. $\beta_{\mathrm{II}} \mathbf{C}$ :

Transmitted light image of efferent ducts in testis. D: The $\beta_{\text {II }}$ antibody does not label cilia in efferent ducts. Note the presence of $\beta_{\mathrm{II}}$ in smooth muscle. $\beta_{\mathrm{III}}$. E: Transmitted light image of efferent ducts in testis. F: The $\beta_{\text {III }}$ antibody does not label cilia in efferent ducts. $\beta_{\text {IV. }}$ G:

Transmitted light image of efferent ducts in testis. H: The $\beta_{\text {IV }}$ antibody labels cilia in efferent ducts. C, cilia; sm, smooth muscle; ct, connective tissue. The scale bars $=15 \mu \mathrm{m}$ for $(\mathrm{A}, \mathrm{B}, \mathrm{G}, \mathrm{H})$ and $40 \mu \mathrm{m}(\mathrm{C}-\mathrm{F})$. 